that, owing to excessive action or inaction of the nerves which affect the calibre of the vessels, the supply of nutrient material may be interfered with without actual abnormality of the vessels ; or it may be that the composition of the blood is altered. Now the primary causes hitherto recognised-such as the abuse of alcohol and morphia, sunstroke, \&c. - are each capable of producing either of these results, and the solution of the difficulty is no nearer. Thus far we can go, and no further, at present; we can conclude that the change in the nervous tissues is due to defective nutrition, such defect being either in the blood itself or in the vessels.

This fact, however, is far from precluding success in treatment. Proceeding empirically, so to speak, it has been found that this condition, when not too far adranced, is capable of improvement by providing the brain with physiological rest. This is done by completely separating the patient from his accustomed surroundings, by varying as much as possible his modes of life, and by carefully avoiding anything like overstrain of the mind. Even under the most favourable circumstances the restoration takes a long time. The patient must be well fed, and for this purpose, in addition to regular meals, there is nothing better than beef-tea and milk. These should be given freely. As regards medicines, strychnina and phosporus are both useful, and great attention must be paid to the prime vice. American writers claim that benefit accrues to these cases by the use of galvanism, and others advise massage, but these remedies act chiefly by the mental effect their employment produces ; and as in these cases, owing to the mental attitude of indifference, there is little or no effect the benefit claimed is very problematical. There is, however, no donbt that the most potent means that exist of allowing the brain to recover itself are by change of Jife and change of habits. Hence it is of great importance for those who have charge of the treatment of cases of this nature to inquire most particularly into the life-history of their patients. Such inquiry will generally throw light upon the real secret. Either it will be found that the overstrain which has caused the mischief has arisen during the educational period of life, or is due to a toogreat indulgence of animal passions, or in mental overwork connected with business, this latter being, perhaps, complicated by the use of stimulants and narcotics taken under the idea that they may in some way be beneficial ; or-what is the most common case-a congenital nervous instability has been at the bottom of the breakdown, which may eventually have been accomplished by any of the above causes working upon an organ radically wrong to start with. However, be the cause what it may, it having once been detected, the true therapeutical indication is to place the patient in circumstances as diametrically opposed thereto as possible. For instance, let the case oe supposed of a man who, with good physical endowments and a strong animal conformation, has over-indulged the propensities to which that kind of nature inclines him who, being well educated, has commenced what has bidden fair to be a successful commercial or professional life, but who, while working his brain to the utmost in a mental sense, has also indulged his animal propensities to the full, and probably more than "the full": such a person experiences some severe mental shock, the loss of a friend, a narrow escape of life, possibly a sunstroke, or some accident which prostrates him on a bed of sickness. Thereupon his friends soon begin to detect that his mental powers have deteriorated: he may regain his bodily health, but in some of the ways mentioned above evidence of nervous dulness is manifest He himself in some degree becomes conscious that he is not equal to his work, and, finally, if he does not, from what looks like mere laziness, neglect his occupation, his occupation neglects him, and he is no longer capable of earning a divelibood. Such a man must, as soon as possible, be placed in changed circumstances. Instead of mental work he must be encouraged to undertake bodily labour; he must give up his animal indulgence and must be made to lead a clean life, with regular rest, regular food, and regular exercise. At first it will be found most difficult to do this. He must be separated from his home, and his old habits must be entirely changed. It may be necessary in some cases to call in the aid of the law in order to attain these ends. In many instances the very complaint renders the patient indifferent to passive change; but it is only by action resembling that of the constant dropping of water which wears the hardest stone that the treatment can be carried out to its utmost extent. And here there is a difficulty extraneous to the patient, or, rather, which bears upon others besides him.

That is the element of time. How soon will he be well? is the constant question of the friends, and it is very difficult to make them understand that it will take months, or perhaps a year, before he will be fit to resume his work. It is wrong to promise a cure in a few weeks. It is simply a farce to induce a man to place himself under treatment for a month. It often takes more than a month to induce such a person to follow advice, especially when that advice is to adopt some scheme of life which is repugnant to his inclinations; but it is thus and thus only that alleviation of the symptoms can be hoped for. $A$ man who for twenty or thirty years has, as I once heard an accomplished physician say, "worked one part of his brain till it has become little more than a rag," and has neglected his other faculties, cannot expect that the damage will ever be repaired unless rest-that is, physiological restis allowed full scope, and so it is with these cases; but they are not hopeless. Given time to apply the remedy the outlook will be far from cheerless; but the other side of the picture is-dementia.

Hendon.

\section{HEMIANASTHESIA AND ATAXY FROM LESION IN THE PONS VAROLII.}

\author{
BY HERBERT H. BROWN, M.D., B.S. LOND., \\ F.R.C.S. ENG.
}

THE patient, a young woman twenty-four years of age, who had enjoyed good health, on April 8th, 1892, while assisting at a school entertainment, suddenly became faint and in rushing towards a window fell to the ground. There was no history of cardiac or renal disease, and there was no evidence of arterial degeneration. After the fall there was no actual loss of consciousness, and she states that she remembers all that took place. When visited an hour afterwards she appeared to be suffering from shock; she could be roused to put out her tongue \&c. when spoken to loudly. No conjunctival reflex could be elicited on either side. On the next day (the 9th), on more complete examination, it was found that the right side of the face was completely paralysed as regarded volitional, emotional and reflex movements. Both pupils were contracted. The eyes could not be moved to the right beyond the middle line. There was absence of sensation over the left side of the body and face. Plantar reflex was absent on the left side. There was some difficulty in swallowing and articulation. There was no motor paralysis of the limbs. The knee-jerks were normal on both sides. There was no deviation of the tongue. The temperature was $100^{\circ} \mathrm{F}$. The pulse was regular and about 90 . Respiration was normal. The conjunctival reflex was now obtainable on the left side, but not on the right. On the following day (the 10th) sensation returned to some extent in the face, but over the left side of the body it was still almost entirely absent. There was internal strabismus of the right eye. During the next few days the patient's condition became much worse. The temperature rose from $101^{\circ}$ to $102^{\circ}$. The pulse was more rapid and about 110 . The tongue was very thickly coated. The breath was foul. The bowels were obstinately constipated. The patient was drowsy, but complained of pain in the head and in the left arm and breast, which she frequently rubbed. Her speech became quite unintelligible and her power of deglutition was very much impaired, so that feeding became very difficult. The tongue deviated to the right for a few days. After about a week improvement took place: the febrile symptoms disappeared, and the power of articulation and deglutition returned, until after a month or six weeks from the onset she was able to feed herself and to get up. There was well-marked internal strabismus of the right eye, diplopia was much complained of, and there was still inability to move the left eye towards the right, but unaccompanied by strabismus. The facial paralysis remained as before. Sensation had returned to a slight extent on the left side of the face, which was now only slightly impaired, but on the left side of the body and limbs was still very imperfect, both as regarded tactile and painful sensations. On the left hand and fingers there was still entire absence of sensation. Muscular sense appeared to be absent on the left side. The patient was unable to tell the position of the limbs or to hold anything in the left hand unless her eyes were fixed upon it. She was quite unable to pick up a small object or to feed 
herself with the left hand. She was able to walk with assistance, but very slowly and unsteadily, and leant over very much to the right side. She could not stand alone. She afterwards improved to a certain extent. She could stand by herself for a short time, and walked with the aid of a stick, but very unsteadily. There was a gradual recovery of sensation, but it remained much impaired, especially in the left hand. The diplopia ceased to be noticeable, and there was some power of movement of the left eye inwards, though the paralysis of the external rectus of the right eye remained. Muscular sense improved, so that she became able to tell the position of her limbs and to hold an object in the left hand with the eyes closed; but there was always great ataxy in all movements of the left hand, and she was unable to pick up a small object such as a pin without great difficulty. The left arm and leg were always blue, cold, and congested when the weather had been at all cold, and she experienced great difficulty in keeping the left hand warm, which also showed a tendency to chilblains. There was a very troublesome ulceration of the right cornea, which continued for many weeks in spite of careful treatment and was accompanied by iritis.

Fifteen months after the onset her condition is as follows : Her general health is good. She has gained considerably in weight, and can walk by herself with the aid of a stick, though with difficulty and very unsteadily. Sensation is present everywhere, but is very deficient on the left hand and fingers. The prick of a pin cannot be localised anywhere on the hand or fingers, and when felt the sensation is delayed. Heat and cold cannot be distinguished on the left side of the body. Tactile sense in the hand is practically absent and is very imperfect over the arm and leg. There is great ataxy in all movements with the left arm. She cannot touch the tip of the nose with the left forefinger when the eyes are closed. She is unable to pick up a pin or perform any delicate operation, and the hand sways about when she attempts to hold it straight out. Sensation in the foot is much less imperfect than in the hand, and the ataxy in the leg is less, though she is unable to stand with the eyes closed. The internal strabismus of the right eye remains as before. The pupils are of normal size and react to light and accommodation. The right eye can now be directed inwards to some extent. The facial paralysis remains absolute, and there is no response to faradaism on the right side of the face. Although she is quite unable to forcibly close the left eye, the lid descends with the right when the eyes are gently closed as for sleep; it does not, however, completely cover the eye, and no effort of the will can close it any further. The knee-jerks are normal and equal on both sides. There is no ankle-clonus. Plantar reflex, though slight on the left side, is obtainable. There is no paralysis of the soft palate on either side.

Remarks.-The diagnosis of the situation of the lesion presents no difficulty, though the nature of the lesion is less clear. The paralysis of the external oblique muscle of the right eye points to a lesion involving the sixth nerve or its nucleus on this side. Since the internal strabismus of the right eye was accompanied by a loss of power of movement of the left eye towards the right it is clear that the nucleus of the sixth nerve, and not the nerve alone, is affected, for it is only in cases in which a lesion involves the nucleus that complete paralysis of the external rectus leading to internal strabismus is accompanied by loss of the conjugate movement of the other eye. The nucleus of the sixth nerve is connected with that of the third nerve on the other side by means of the posterior longitudinal bundle. The facial paralysis on the right side is total for all kinds of movement -volitional, emotional and reflex-and is accompanied by degeneration of the facial nerve, as evidenced by the absence of response to faradaism. It is clear, therefore, that the paralysis is due to a lesion of the nerve itself or of its nucleus in the pons. The fact that the orbicularis oris muscle is paralysed indicates that the lesion involves the nerve and not its nucleus only, for it appears that that muscle derives its nerve supply from fibres which arise at the bypoglossal nucleus but run in the course of the facial nerve. A single lesion involving the facial nerve and the nucleus of the sixth nerve can only be situated in the position indicated in the diagram, which represents a transverse section in the lower part of the pons. In this situation the facial nerve, which is seen cut across twice, loops closely round the nucleus of the sixth nerve, so that a gross lesion, such as embolism or hæmorrhage, which destroyed the one, could not fail to destroy the other. The nucleus of the sixtb nerve is situated in the tegmental region of the pons, in which sensation is conducted upwards from the opposite side of the body. It is supposec that impulses of muscular sense are conreyed in the tract of the fillet; if this is so, the lesion must have extended as far forwards as that tract, which lies at the anterior part of the reticular formation. It is obviously a small lesion, since it does not spread in the slightest degree inwards beyond the middle line, nor outwards as far as the fifth nerve, the ascending root of which is situated immediately outside the seventh nerve in the descending part of its course (see diagram). During the first few hours after the onset the conjunctival reflex was absent on the left side, and there was no sensation on the left side of the face. The sensory tract conducting upwards from the fifth nerve of the other side to the cortex, which crosses in the pons considerably above the level of the nucleus of the sixth nerve, must have been greatly interfered with. The immediate effect was probably in great measure due to inhibition, since it passed off in the course of a day or two; some slight interference with sensation has, however, remained, which would lead one to suppose that the lesion extends upwards for some little distance in the reticular formation. The febrile condition which ensued a few days after the onset, and was accompanied by great impairment of swallowing and articulation and deviation of the tongue, \&c., was due to the inflammatory reaction which follows hæmorrhage or softening from vascular occlusion, affecting the centres of the glossopharyngeal and hypoglossal nerves, which lie a little below the nucleus of the sixth nerve. It is interesting to note that

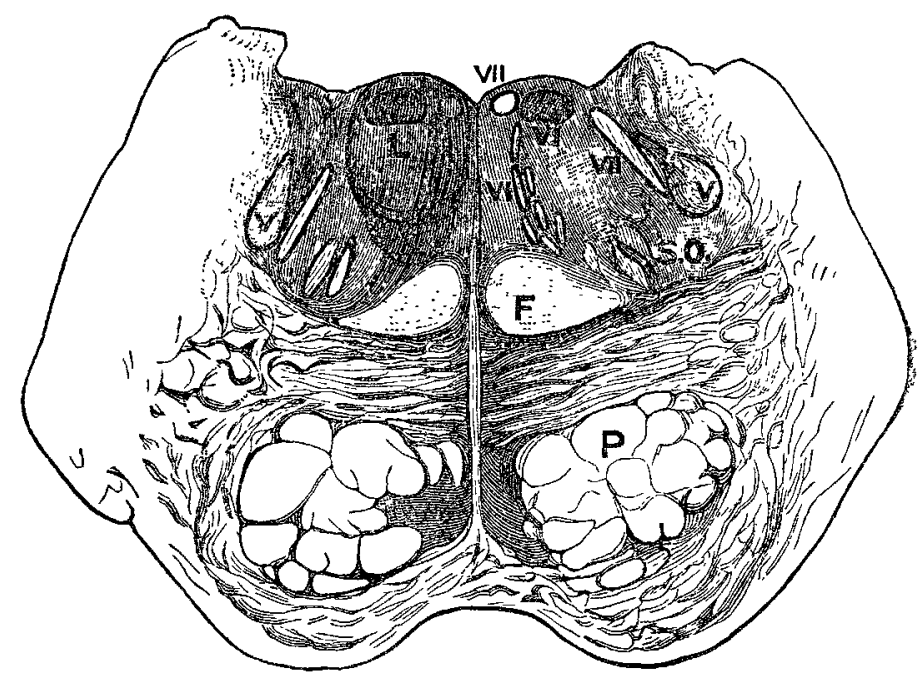

I, Situation of lesion. F, Fillet. P, Pyramidal tract. VIr, Facial nerve. VI, Sixth nerve. VI*, Nucleus of sixth. V, Ascending

sensation in the hand is now, after more than a year has elapsed, very imperfect, whereas in the lower limbs and trunk it is only slightly impaired; this appears to resemble the condition which follows a unilateral lesion in the motor tract, and would seem to be due to the fact that sensaticn as well as motor power in the upper limb, and especially in the hand, are almost entirely represented in the opposite hemisphere, whereas in the lower limb the hemisphere of the same side can take a greater share in sensory as well as in motor representation. The muscular incoördination and vaso-motor paresis in the left hand are also interesting. The diagnosis of the nature of the lesion presents a greater difficulty. It apparently, from the sudden character of the onset, rests between hæmorrbage and embolism. The symptoms are common to both. A small hæmorrhage in the pons is not necessarily accompanied by loss of consciousness, and the inflammatory reaction, though more marked in cases of softening, also occurs after hæmorrhage. There is no evidence of cardiac disease which might lead to embolism, or of renal disease or of arterial degeneration, which might render hæmorrhage more probable. The age of the patient (about twenty-four) does not exclude the possibility of bæmorrhage, though embolism is more frequent.

P.S.--Since the above was written there has been very little change in the patient's condition. The muscular incoordination is still very great; the hand sways about on any attempt at movement, and the fingers are flexed and extended like those of an infant, so that for all delicate manipulations the hand is quite useless. She still walks very unsteadily with the aid of a stick. The left hand is bluer and colder than the right when the weather is cold, and sensation is 
very imperfect, so that the prick of a pin, though just felt, cannot be localised upon any of the fingers. Dr. Gowers has suggested to me that the lesion may be due to the sudden thrombosis of a small vessel ; this, he thinks, is a probable cause of hemiplegia in young adults in whom there is no evidence of cardiac or arterial disease.

Museum-street, Ipswich.

\section{THE PHYSIOLOGICAL EFFECTS OF HIGH FREQUENCY ELECTRIC CURRENTS.}

\section{BY W. S. H E D E Y, M. D. EDIN., M.R.C.S. ENG.}

MR. A. C. Stinton's letter in THE LANCeT of Oct. 14th will not only be appreciated by medical men as a valuable contribution to our knowledge of a new and difficult subject, but it will be accepted also as an indication that the electrical expert is willing to aid in the efforts of the profession to decharlatanise medical electricity and to reduce some at least of its problems to a question of sound physics. In referring to an article of mine which appeared in THE LANCE: of Ang. 19th, Mr. Swinton correctly states that the view therein adopted that high frequency currents are harmless mainly because of their small current strength is one previously put forward by him in the Philosophical Magazine of February hast. It might also have been added, and no doubt would have been so had Mr. Swinton been aware of the fact, that before the appearance of the article in the Philosophical Magazine II, and before me the Electrical Rtview, had accepted this principle and referred to the "whittling down" of current strength by the various transformations to which it had been subjected as a probable cause of this and many similar phenomena. This seems to be evidenced by an article on the physiological effects of alternating currents published in THE LANCET of Dec. $24 \mathrm{th}, 1892$, and by the pages of the Electrical Revien. With the knowledge that exists of the surface transmission of high frequency currents along metallic conductors, Mr. Swinton's explanation of the power of such currents to light incandescent lamps becomes a very probable one; but when the human body becomes the conductor there seems to be no good evidence to show how such currents are transmitted unless (and this the present state of the question seems scarcely to warrant) the physiological effects claimed for them are accepted as a proof that they deeply penetrate the organism. This is a question in biological physics concerning which light and leading are still sought for. Mr. Swinton suggests a general law that, apart from some possible minor influences of frequency and abruptness of alternation, the physiological effects of electric currents are mainly proportional to their electrolytic effects. Other things being equal, this is probably true. But it seems to minimise the importance of other factors, and, taken as a law, to fall far short of the facts. As an instance those most obrious of all electro-physiological phenomena, the neuromuscular effects that follow electric excitation, may be cited. Putting aside for the moment the influence of current density, an old and familiar experiment, in which a voltameter, an interrupting wheel, and a frog à la Galvani ("physiological limb") are connected up in a continuous current circuit, may be considered. With the wheel at rest gas is disengaged and there is no visible muscular contraction. Once the wheel is put into motion evolution of gas nearly ceases, and the muscle is seen to strongly contract. In other words, unless a certain current is made aná broken no visible muscular movement occurs. The mere passage of the current, be the electrolytic effect what it may, fails to produce visible contraction. Here motor reaction is proportional to the ariation of the potential and to the suddenness with which that variation is made, as well as (no doubt) to the strength of the current used. But the question is not even so simple as this. With the "interrupted Franklinic" current there is obtained a maximum motor effect with a minimum amount of sensation-viz, violent muscular contraction with practical immunity from pain. How does current strength help here? If smallness of quantity accounts for the absence of sensory effect it can scarcely be invoked also to account for the marked presence of motor effect. Further, how does such a law cover the phenomena of "make" and "break" and the reversal of the formula in the "reaction of degeneration" "or bow does it account for those conditions of altered excitability known as "anelectrotonic" and "katelectrotonic"? In these cases there are varying physiological effects with the same current strength. How far the ordinary laws of physios and how far "vital" endowments of living structure account for such phenomena have yet to be ascertained. It would appear that we must still content ourselves with the statement that the effects of electric currents on the body depend not only upon current strength but on the mode in which such current strength is presented-i.e, that physiological effects are proportional not only to the quantity of electricity but also to its modality.

Western-terrace Brighton.

\section{CASE OF ODONTOMA OF THE LOWER JAW; REMOVAL.}

BY ALERED SWANN, M.D., M.R.C.S., L.S.A., STRGEON TO THE BATLEY AND DISTRICT HOSPITAL.

ThE following case seems to me to be worth recording on account of its rarity. Mr. Christopher Heath says, in his "Lectures on Diseases of the Jaws," that "there are, I believe, but nine cases of this form of odontoma recorded, and these all occurred in the lower jaw."

A woman forty years of age, a weaver, came under my care in the year 1884, with the following history. Shortly before seeing me she received a blow from the "picker" of her loom over the right side of the lower jaw. Soon afterwards a hard swelling formed, which was poulticed until it burst. She then consulted me regarding the sinus in her face, and on looking inside her mouth I found some carious stumps-viz., the canine and anterior bicuspid-which looked as if they might be responsible for the abscess. These I extracted. The swelling, however, became no less, but continued to discharge until September, 1889, when sheagain consulted me. At this time the tumour had obviously enlarged, and there was a sinus leading down to what felt like roughened bone. I advised her to come into the hospital with a view to making an exploratory operation and of removing any sequestrum that might be found. On admission she was suffering from a tumour the size of a large filbert, situated on the right side of the chin and directly below the position formerly occupied by the canine and anterior bicuspid teeth. At the margin of the chin and below the tumour there was a sinus discharging some thin and very offensive pus. On Sept. 28th, 1889, the patient having been placed under the influence of ether, I made a submental incision, and, turning up the upper flap, found that there was, deeply situated in the substance of the lower jaw on its anterior aspect, a hard dentine-like growth which required the free use of chisel and mallet for its removal. The posterior bicuspid was displaced to some extent, the fang lying obliquely in the jaw, with its crown looking towards the mouth. The wound was washed out with salufer solution and plugged with iodoform and lint. The patient left the hospital cured in about three weeks.

Remarks. - When I had removed the foregoing tumour I was puzzled to know what its nature was, and, after submitting it to various pathological friends and receiving no definite information, I sent it to Mr. Christopher Heath, who at once informed me that it was an odontoma, and he kindly forwarded me his "Lectures on Diseases of the Jaws," where at p. 36 will be found a description of all the known cases that have been reported. The specimen has now found a home in the museum of the Royal College of Surgeons of England.

The patient called to consult me on Sept. 29th last, just four years after the operation, regarding the advisability of having artificial teeth applied. The alveolus had slightly fallen in where the growth existed, but otherwise she was perfectly well.

Batley, Yorks.

Surgical AID Soctety (Brighton and Hove BRANCH). - The first annual meeting of this Society was held on the 28th ult., under the presidency of the Mayor, Dr. Ewart. A most satisfactory report of the year's work was read by the secretary, and the sum received in subscriptions amounted to over $\$ 196$. 